\title{
The influence of slope aspect on soil moisture
}

\author{
Csaba VARGA, ${ }^{1}$ Levente CSISZÉR ${ }^{1}$ \\ ${ }^{1}$ Sapientia Hungarian University of Transylvania (Cluj-Napoca, Romania), \\ Department of Horticulture, Faculty of Technical and Human Sciences, Târgu-Mureş, \\ e-mail:vargacsab@yahoo.com, csiszer.levente@ms.sapientia.ro
}

Manuscript received: October 2020; revised: 2 November 2020; accepted: 12 November 2020

\begin{abstract}
In this research, we investigated the variability of soil moisture on two slopes of opposite aspect (a northern slope and a southern slope) but with the same soil type. To identify the spatial disposal of the soil type on both slopes, we georeferenced the paper-based soil map of Sfântu Gheorghe, using the QGIS platform. In order to use the correct slope aspect, we used a numerical model of the terrain (relief). The research plot was soil sampled at the depth of $10 \mathrm{~cm}$ on two different dates: on 7 November 2019 and on 3 March 2020, using a Buerkle soil sampler.

Gravimetric method was used to determine the soil moisture values that proved to be the most accurate for our purpose.

The soil moisture values, obtained in weight percentage, were assigned to the coordinates of the sampling points, and soil moisture maps were generated in QGIS for both slopes and for both sampling dates. These maps gave us the opportunity to evaluate the variability in time of the soil moisture distribution on the sample plots.

The water holding capacity of the soils is mostly influenced by their organic $\mathrm{C}$ content. So, the total organic carbon content of the soil from the sampling plots was measured using the Tyurin method.
\end{abstract}

Keywords: georeference, same soil types, grid soil sampling, organic carbon content

\section{Introduction}

The slope aspect is an abiotic cultivation factor, element of the relief, as one of the main pedogenetic factors. Slopes having different aspects have a wide range of microclimatic properties. The development of these different endowments is determined by the different values of the insolation. The quantity of the incident solar radiation influences the pedogenetic processes, the structure of the soils, and their texture. The regime of the temperature in the soil has an indisputable effect on the total edaphon, which contributes to the decomposition 
of the organic matter and to the formation of humus. All these parameters influence the seasonal water management of the soils and the changes in their moisture content [1]. Practising an efficient crop production in today's climatic and economic environment is only possible by the thorough knowledge of the endowments of the production plot [2].

Increasingly advanced GIS and satellite positioning tools are expanding the possibilities for investigating the influence of the slope aspect on different properties of the soils.

By georeferencing the paper-based soils map of Sfântu-Gheorghe, we had the opportunity to do our research on the same soil type (faeoziom), while the grid-point sampling method allowed us to compare more efficiently the samples from multiple sampling occasions and to better understand the results.

\section{Materials and methods}

\section{Georeferencing the soil map}

In order to find out whether there is the same soil type on the northern and southern slopes in the surroundings of Sfântu-Gheorghe, it was necessary to georeference the paper-based soil map, issued by the Office of Pedological and Agrochemical Studies (O.S.P.A.) in 1999, as the map does not show the topography and elevation values.

The soil map was geoferenced using the image-to-image method (Fig. 1), based on a georeferenced orthophoto. For the operation, we have selected points with known coordinates in the target coordinate system, and these could also been identified on the raster [3].

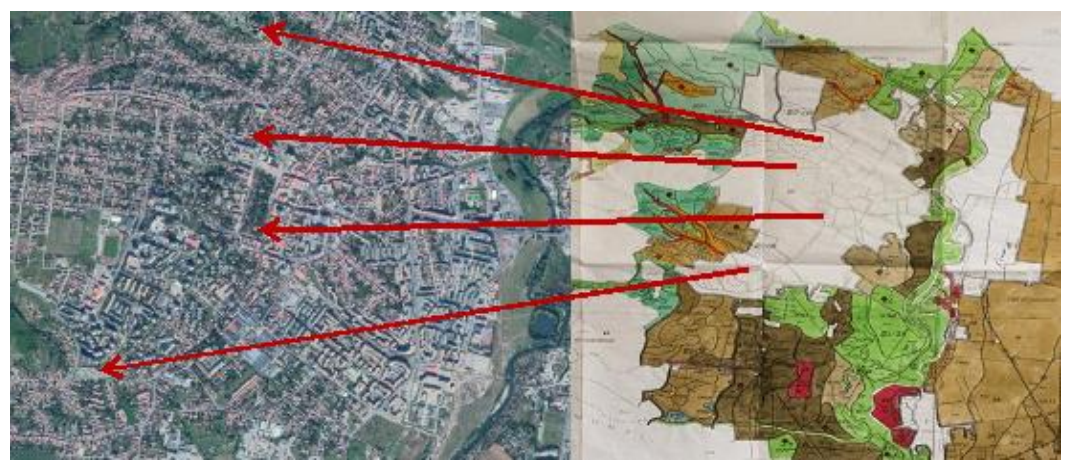

Figure 1. Georeferencing image to image 
After georeferencing, the soil map became comparable with a topographic map. We overlaid the two maps and were able to identify a northern slope and a southern slope having the same soil type.

\section{Verification of slope aspect by generating a slope aspect map}

To prove that the two slopes we have selected truly dispose of the northern and the southern aspect, we generated a slope aspect map in QGIS [4]. To generate this map, we used a digital elevation model in GeoTIFF format (Fig. 2) with a resolution of $25 \mathrm{~m}$. This means that a pixel contains the average elevation data of a $25 \times 25 \mathrm{~m}$ plot [5].

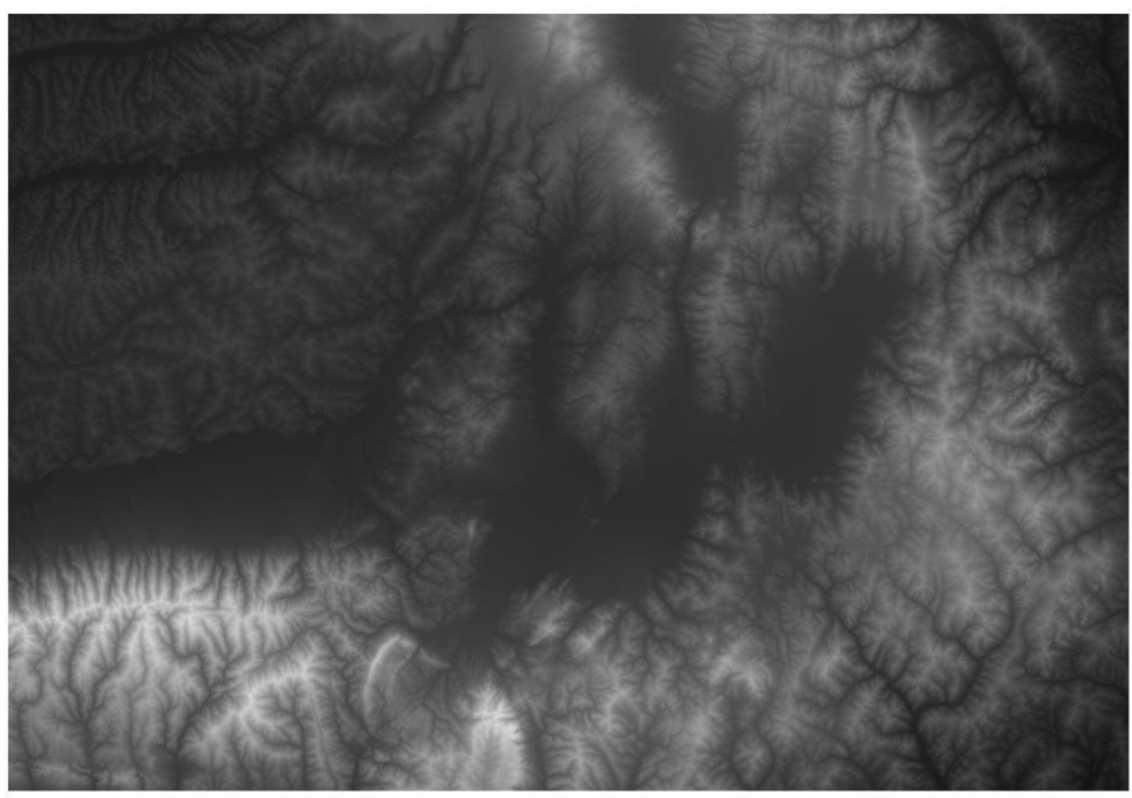

Figure 2. Digital elevation model

Before selecting the sampling plots on the slopes, topographic measurements were made as part of a preliminary field survey. These measurements were made with a Horizon Kronos C3 RTK (Real-Time Kinematic). With these measurements, we recorded the $\mathrm{X}$ and $\mathrm{Y}$ coordinates of the points in Stereo 70 projection and their elevation. The corrections were provided by the ROMPOS system [6]. Data were processed in QGIS, and an elevation curve map could be generated for the two plots/part of the two slopes (Map 1 and Map 2). 


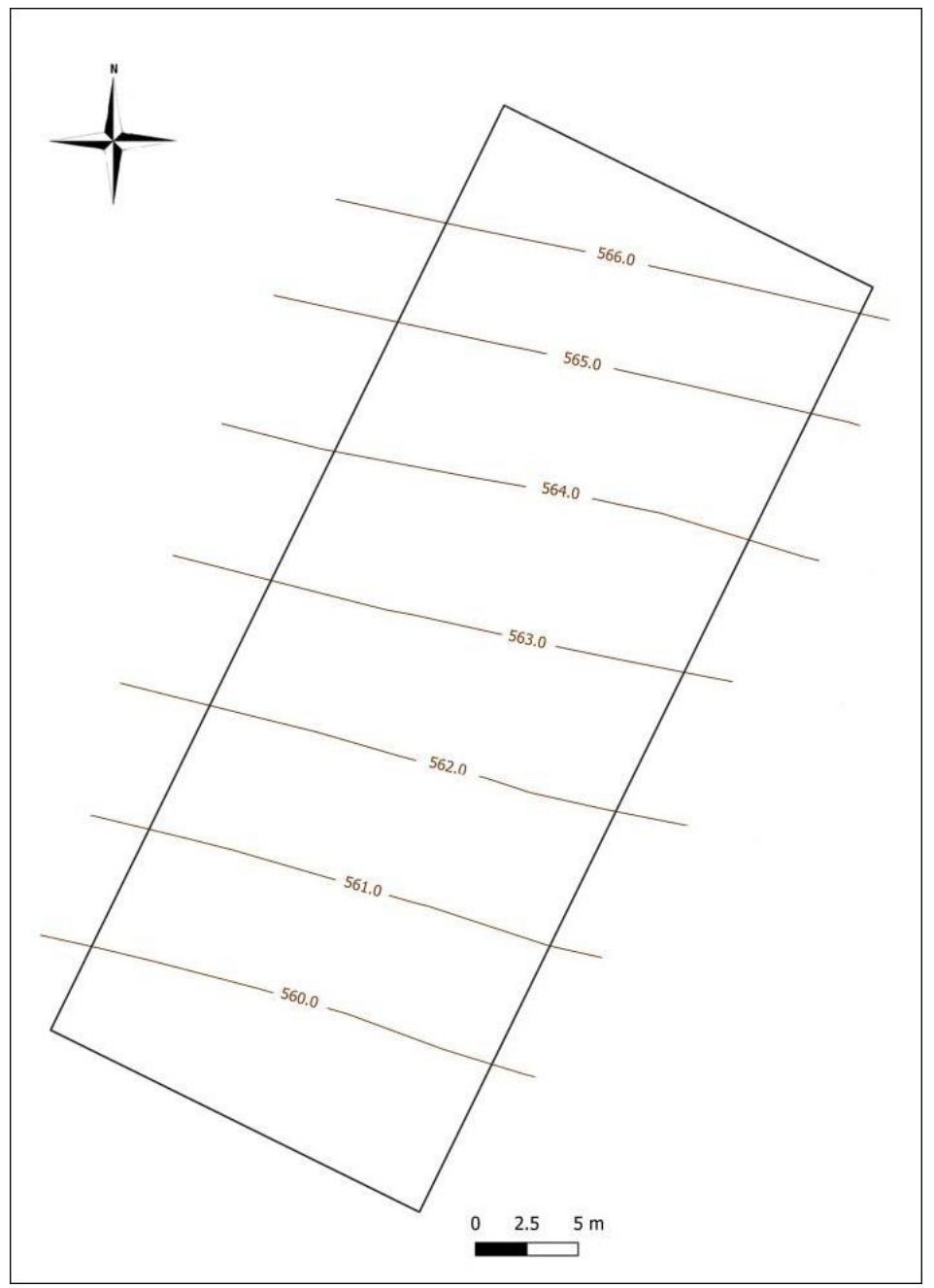

Map 1. The elevation curve map of the southern slope 


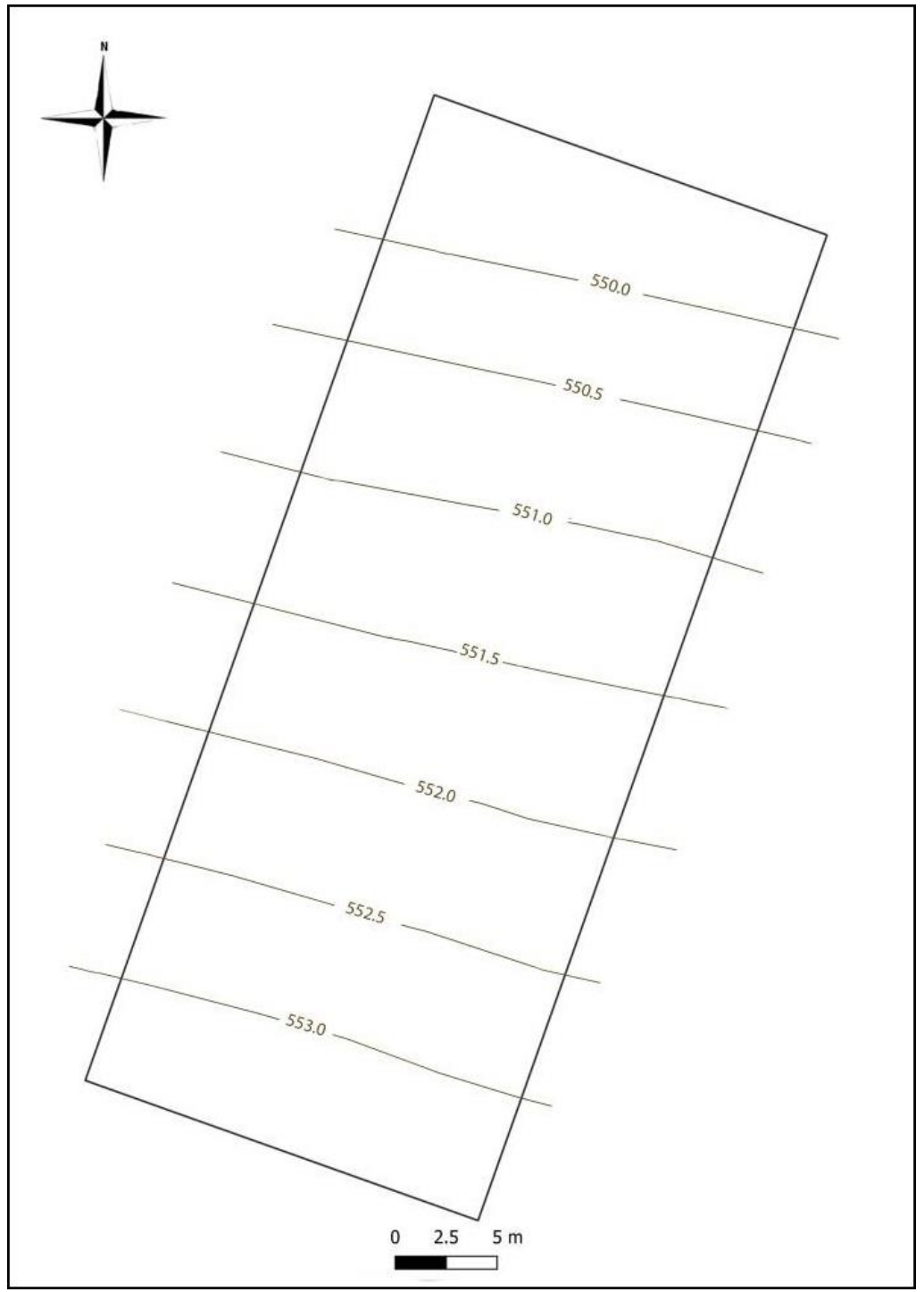

Map 2. The elevation curve map of the northern slope

Editing the sampling grid in QGIS

Two sampling plots were established, one on the northern slope and one on the southern slope. Essentially, this means two sampling grids of 1,000 sq. m edited in QGIS (Fig. 2), having the longer side downwards the slope. 


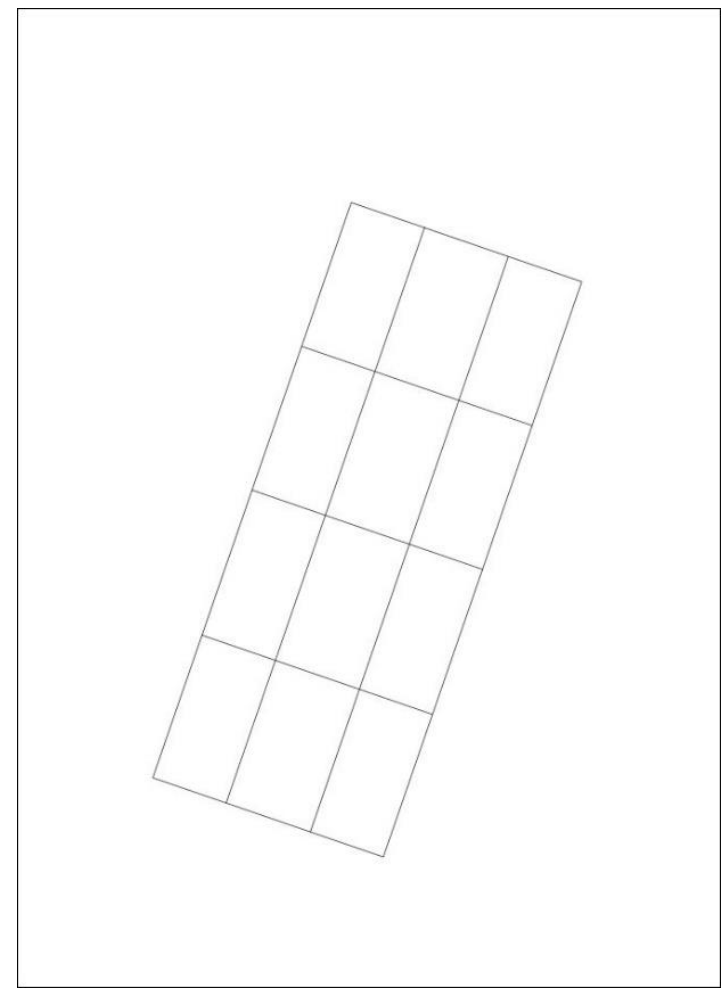

Figure 3. Sampling grid

Sampling

The soil samples were collected on two dates: on 7 November 1999 and on 3 March 2020.

The soil samples were collected at the grid points; so, we needed to set these points as topographical ones on the sampling plot. The operation was made with the same Kronos Horizon RTK (Real-Time Kinematic), controlled by Carlson SurvCE 6.0 software. The sampling was made with a Buerkle soil sampler from the upper $10 \mathrm{~cm}$ soil layer. From the same point, we took samples both for soil moisture and total organic $\mathrm{C}$ content determinations.

Generating the map of the soil moisture distribution of the sampling plots

The soil moisture of the samples was determined with the gravimetric method [7]. These values were ordered in a table with the coordinates and 
elevations of the sampling grid points. We obtained a table having 4 values for each point, and it was introduced in QGIS in CSV format [8] (Table 1).

Table 1. The coordinates of the southern slope sampling points with moisture

\begin{tabular}{|c|c|c|c|}
\hline Sampling points & Northing & Easting & Soil moisture \% \\
\hline S1 & 484616.237 & 559573.968 & 28.4 \\
\hline S2 & 484619.398 & 559567.41 & 25 \\
\hline S3 & 484608.14 & 559561.987 & 27.3 \\
\hline S4 & 484604.973 & 559568.551 & 22.2 \\
\hline S5 & 484593.613 & 559563.088 & 24.7 \\
\hline S6 & 484596.78 & 559556.516 & 22 \\
\hline
\end{tabular}

Table 2. The coordinates of the northern slope sampling points with moisture

\begin{tabular}{|c|c|c|c|}
\hline Sampling points & Northing & Easting & Soil moisture \% \\
\hline N1 & 487477.848 & 560973.336 & 21.5 \\
\hline N2 & 487480.223 & 560966.439 & 20.5 \\
\hline N3 & 487492.146 & 560970.541 & 22.3 \\
\hline N4 & 487489.77 & 560977.431 & 21.6 \\
\hline N5 & 487501.591 & 560981.491 & 19.8 \\
\hline N6 & 487503.962 & 560974.607 & 22.5 \\
\hline
\end{tabular}

Determination of the total organic C content of the soil using the Tyurin method

Total organic $\mathrm{C}$ is one of the matters that can absorb a great amount of water. So, we considered that its content can influence the quantity of water restrained by the soil [9].

The soil samples were prepared by sieving through a $2 \mathrm{~mm}$ sieve, and any visible organic residues were removed. We measured $0.1-0.5 \mathrm{~g}$ of soil according to their colour and put them in tubes. We added $10 \mathrm{ml}$ of dichromate solution acting as an oxidizing agent, covered the tubes with glass funnels, heated them in a water bath to the boiling point, and boiled the samples slowly for 5 minutes. After that, the samples were titrated with 0.2 normal Mohr salt; essentially, we re-titrated the dichromate which was not used during the oxidation process [9], [10]. 


\section{Results and discussions}

From the moisture values determined on the two sampling dates, soil moisture maps were interpolated within the sampling plots. The maps offer us the opportunity to compare the data and establish correlations.

Autumn sampling was preceded by a dry period of low rainfall. Our soil moisture determinations reached values between 16 and $21 \%$ on the southern slope. On the northern one, they were similar, i.e. between 16 and $21 \%$.

Spring sampling soil moisture values were lower on the northern slope (compared to the southern slope values), ranging between 19.8 and 22.5\% (Map 3 ), and so higher than in autumn with an average of $1 \%$.

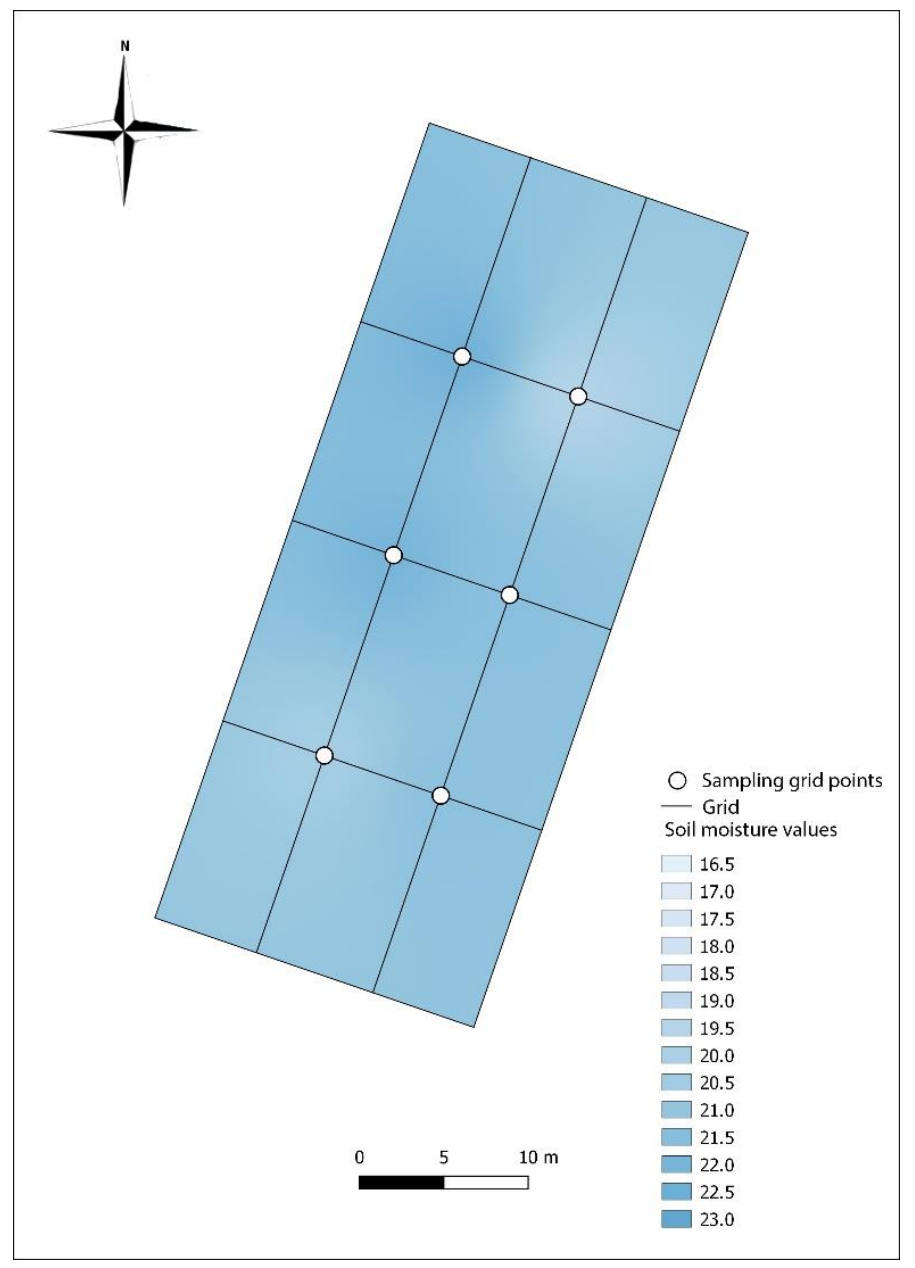

Map 3. The northern slope soil moisture distribution map in March 


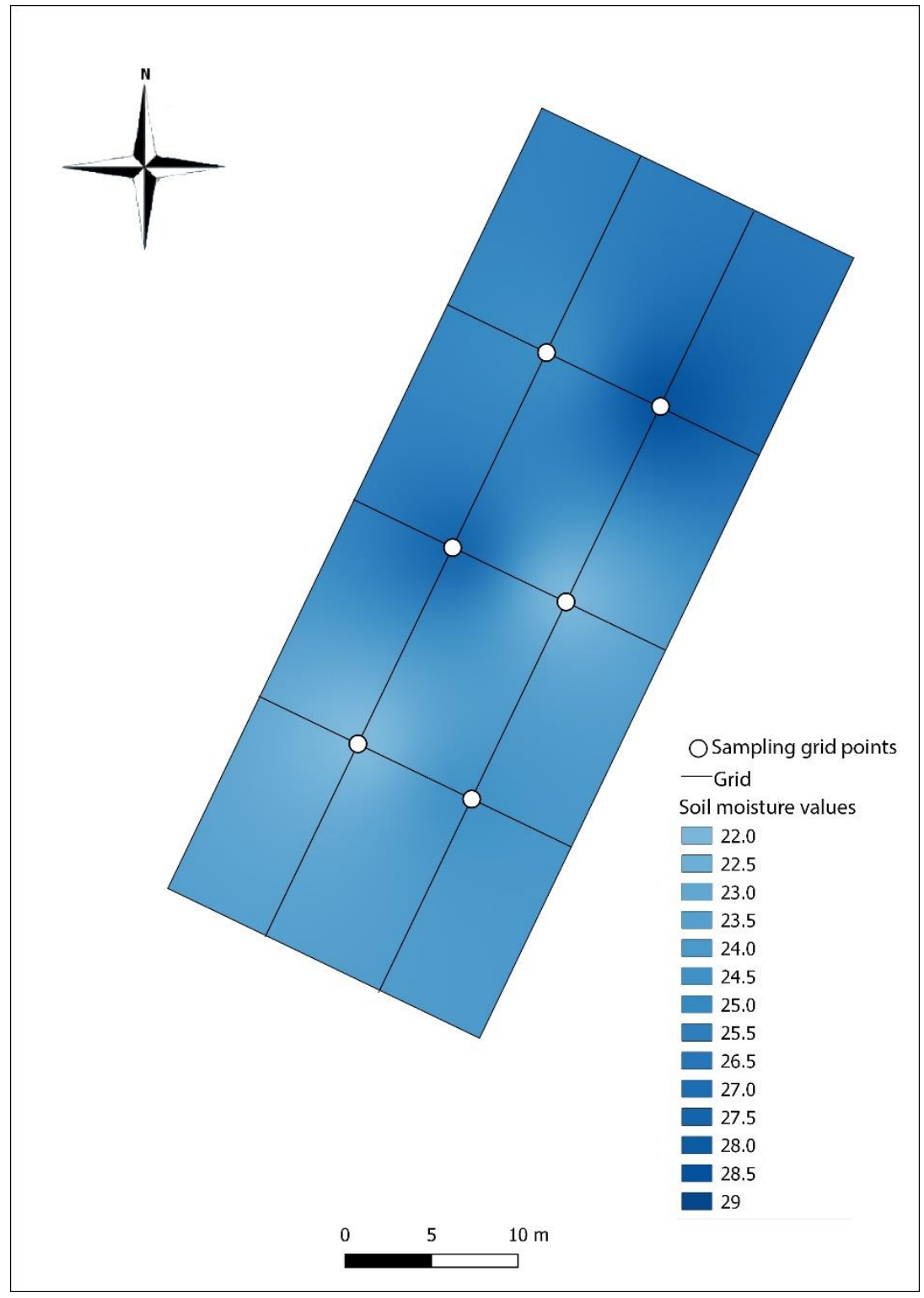

Map 4. The southern slope soil moisture distribution map in March

On the southern slope, these values were higher, between 22 and $28.4 \%$ (Map 4), with an average difference of $6 \%$ compared to the autumn determinations. 
The values of the total organic carbon are evaluated through the graphs below, where the standard deviation can also be seen. On the northern slope, the values were between 2.7 and $4.2 \%$, and just two samples reached $4 \%$ (Fig. 5). On the southern slope, all values were over 4\% (Fig. 6).

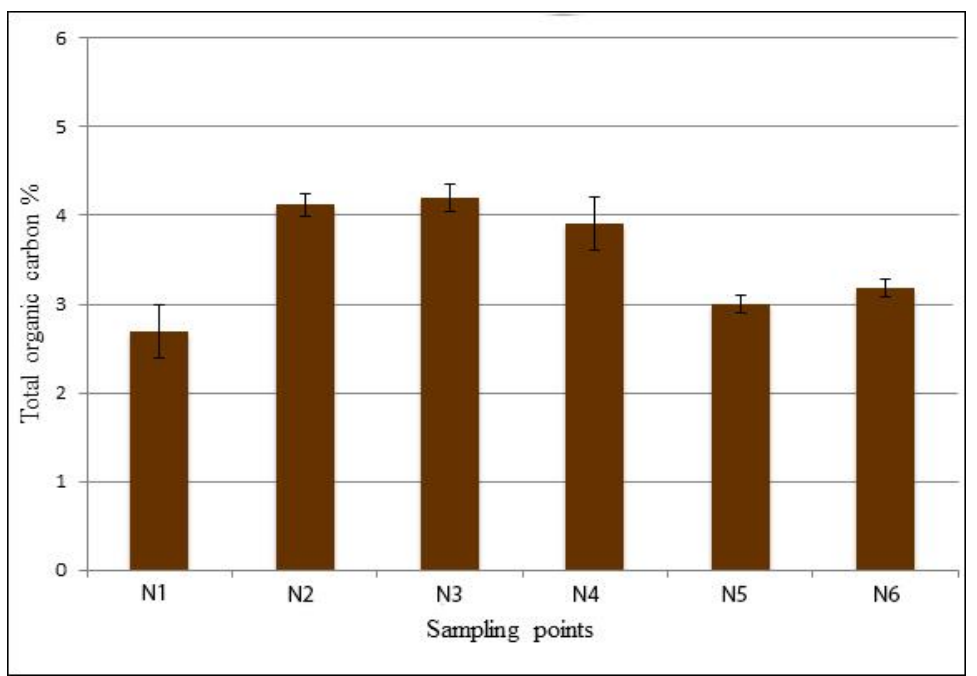

Figure 5. The northern aspect slope - total organic $\mathrm{C}$ content in percentage

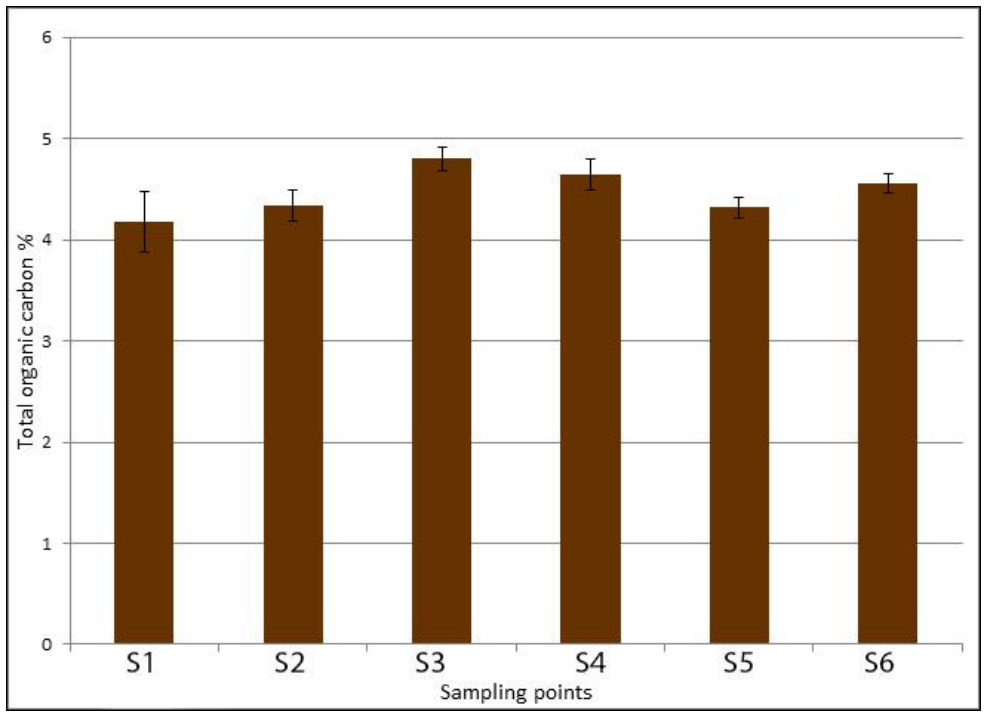

Figure 6. The southern aspect slope - total organic $\mathrm{C}$ content in percentage 


\section{Conclusions}

These new methods like GIS and precision soil sampling provide new opportunities for a more complex study of the effect of slope aspect on soil moisture.

By georeferencing the soil map of Sfântu-Gheorghe in the Romanian projection system (Stereo 70), we opened up the opportunity for the information provided by this map to be compared - overlaid in GIS - to information provided by other maps, topographic information, and orthophotos. Through this map, we could do soil moisture measurements on the same soil type on different aspect slopes (a northern and a southern one). In addition, on both selected sample plots, we had the opportunity to make "virtual" grids and to set the grid points on the field, which became the soil sampling points.

The method of grid-point sampling allowed us to do the sampling always from same spot on each sampling date. As a continuation of the research, besides soil moisture, we can determine other soil properties connected to moisture as the samples can be collected from the same grid points already set.

The soil moisture values obtained on the northern and southern slope were alike on the autumn sample collection date. At the spring sample collection, the measured values were different. On the southern slope, the values were higher than on the northern one.

As the total organic carbon content of the soil plays a significant role in the variation of the soil water retention capacity, we determined this parameter too for each grid point for both sample plots. According to our results, the southern aspect slope sample plot has reached higher values. Therfore, we can suppose that the higher soil moisture values on the southern slope sample plot are due to the higher total organic carbon content [5]. However, more accurate conclusions can be done by simply carrying on with the measurements, evaluating the precipitation values, and determining the dominant wind direction (as a factor in the value of evapotranspiration). By making soil moisture measurements on a weekly basis, it will be possible to get an image about the drying out of the soil.

On the other hand, it is necessary to determine the total soil clay content as, besides the total organic carbon content, the clay colloid is able to absorb a great amount of water.

By georeferencing the soil map and by grid point sampling, we introduced new research procedures that will facilitate comparability between the studied slopes. 


\section{References}

[1] Reid, I. (1973), The influence of slope orientation upon the soil moisture regime, and its hydrogeomorphological significance. Journal of Hydrology 19(4), 309-321.

[2] Franzluebbers, A. J. (2002), Water infiltration and soil structure related to organic matter and its stratification with depth. Soil \& Tillage Research 66, 197-205.

[3] Siki, Z. (n.d.), Raszter georeferálás QGIS-ben. http://www.agt.bme.hu/gis/qgis/georeferencer. pdf (last accessed on: 12 May 2020).

[4] Telbisz, T., Székely, B. Timár, G. (2013), Digitális terepmodellek. ELTE TTK, Földrajz- és Földtudományi Intézet, Természetföldrajzi Tanszék. http://tef.elte.hu/phocadownload/ TelbiszSzekelyTimar_DigitalisTerepmodellek.pdf (last accessed on: 11 May 2020).

[5] https://land.copernicus.eu/imagery-in-situ/eu-dem/eu-dem-v1.1?tab=download (last accessed on: 21 May 2020).

[6] https://rompos.ro/.31 October 2019 (last accessed on: 3 March 2020).

[7] Stefanovits, P., Filep, Gy., Füleky, Gy. (1999), Talajtan. Budapest: Mezőgazda Kiadó.

[8] Varga, G. (2013), Geomorfológiai térképezés. Pécsi Tudományegyetem. http://eta.bibl.uszeged.hu/1305/1/geomorfologiai_terkepezes.pdf (last accessed on: 10 May 2020).

[9] Jakab, S., Krézsek, J. (2008), Talajtani és agrokémiai laborgyakorlatok. Târgu-Mureș: University Press.

[10] Violina, R. A., Vanja, I. A., Krasimir, I. I., Penka, A. L. (2014), Comparative study of titrimetric methods for determination of organic carbon in soils, compost and sludge. Bulgarian Chemical Communications 8(3), 430-440. 